\title{
Timing of umbilical cord clamping of term infants
}

\author{
José María Ceriani Cernadas, M.D..$^{a, b}$
}

\begin{abstract}
For at least over 200 years, multiple controversies have arisen around the timing of umbilical cord clamping. In the past decades, early cord clamping (within thefirst 15 seconds) had markedly prevailed. Only in the $21^{\text {st }}$ century, randomized controlled trials have demonstrated the benefits of delayed cord clamping (at 2-3 minutes). Delayed cord clamping has been practiced in obstetrics based on the recommendations made by scientific societies and in systematic reviews, which have provided solid evidence to support this practice in term infants.

This review describes the most relevant factors supporting the use of delayed cord clamping in term infants. It points out the essential role played by physiologicalmechanisms which, undoubtedly, allow us to understand the benefits of delayed cord clamping and advise us to wait for whatnature has established. Other relevant aspects supporting delayed cord clamping are also described here. Key words: clamping, umbilical cord, placental transfusion, neonatal transition, iron deficiency.
\end{abstract}

http:/ / dx.doi.org/10.5546/aap.2017.eng.188

To cite: Ceriani Cernadas JM. Timing of umbilical cord clamping of term infants. Arch Argent Pediatr 2017;115(2):188-194.

a. Division of Neonatology and Teaching Institute of Hospital Italiano de Buenos Aires.

b. Council of Publications of the Argentine Society of Pediatrics.

E-mail address:

José María Ceriani

Cernadas, M.D.:

jose.ceriani@

hospitalitaliano.org.ar

Funding:

None.

Conflict of interest:

None.

Received: 10-11-2016 Accepted: 10-14-2016 obstetrician who also devoted his ought to be; a part of the blood being left in the placenta, which ought to have been in the child."

Pierre Budin, a renowned French time to newborn infant (NBI) care, is considered the father of neonatology. In 1875, Budin published an article discussing the right timing for cord clamping. ${ }^{2}$ In 1975, this article was commented in Pediatrics under a suggestive title: "100 years on, and still no answer. "3 Nothing had changed after so many years.

In the second half of the $20^{\text {th }}$ century, immediate cord clamping became the generalized practice in Western countries. Several studies done in a small number of patients and published in the 1960s and 1970s s-8 $^{4}$ strongly supported immediate cord clamping but there was no evidence to endorse this practice.

Only in this century, well-designed studies have been published that have settled some of the disputes. The current evidence is solid enough to confirm the undeniable benefits of delayed cord clamping for term infants (TIs). ${ }^{9-11}$

To understand the basis of such assertion, the main factors involved in delayed cord clamping of TIs are described below.

\section{Physiological aspects}

Physiological mechanisms play an essential role in the outcomes observed when the cord is clamped not earlier than 1 minute after birth. For this reason, it is critical to know the precise action of these mechanisms to understand their effects on NBIs.

\section{Placental transfusion}

This is the transfer of blood from the placenta to the infant. It is a very important physiological mechanism and the basis to understand the differences in cord clamping timing and its effects on the infant. At 1 minute, NBIs receive $80 \mathrm{~mL}$ of 
blood; at 2-3 minutes, $100 \mathrm{~mL}$; accounting for approximately $30-35 \mathrm{~mL} / \mathrm{kg}$, volume that is $75 \%$ higher than with early clamping.

\section{Iron supply during placental transfusion}

At birth, TIs have a $75 \mathrm{mg} / \mathrm{kg}$ iron (Fe) store; with delayed cord clamping and placental transfusion, TIs receive an additional $40 \mathrm{mg}$ of $\mathrm{Fe}$ at 1 minute and $50 \mathrm{mg}$ at 3 minutes (Figure 1). This way, TIs have a body iron store of $115-125 \mathrm{mg} /$ $\mathrm{kg}$, which is enough to prevent iron deficiency in the first 6 months of life, and probably until they turn 1 year old.

In a study conducted in our setting, ${ }^{12}$ blood ferritin levels at 6 months old were significantly higher among infants whose cord was clamped at 3 minutes versus during the first seconds. Other authors have described similar results. ${ }^{13-23}$

Such effect is very important for the future of children considering that iron deficiency in the early stages may be harmful to the central nervous system and result in neurocognitive disorders. In addition, iron deficiency is the main cause of anemia, a severe condition in developing countries, although less serious in developed countries. ${ }^{24-26}$

\section{First breath and timing of cord clamping}

Several studies have demonstrated that cord clamping timing is greatly relevant for the time of the first breath and for other major aspects of the physiological adaptation to extrauterine life. In a research conducted in sheep, Bhatt et al. ${ }^{27}$ studied the influence of delayed cord clamping on ventilation and on cardiovascular and cerebral hemodynamic stability. Their results showed that when clamping was delayed at least until after the first breath, cardiovascular function improved markedly based on the increased pulmonary blood flow in the NBI and the resulting cerebral hemodynamic stability in the key moments of postnatal transition. In addition, these results indicated that delaying cord clamping until after the onset of ventilation led to a better NBI adaptation, one of the most significant benefits of delayed cord clamping.

Knowing these mechanisms indicates that if a baby is cyanotic at birth, the cord should not be clamped immediately, a very common but inappropriate practice. Early cord clamping will only worsen the infant's clinical status because it causes a noticeable restriction of cardiac output and therefore increases hypoxia. An increased cardiac output is essential to counteract the effects of hypoxemia; for this reason, limiting or preventing the rise in cardiac output exposes the baby to hypoxia-ischemia.

A study conducted in Africa in an extensive cohort of $15563 \mathrm{NBIs}^{28}$ reviewed the relationship between cord clamping timing and the spontaneous onset of breath and infants' clinical course in the first 24 hours of life. Results showed that the risk of death or postdischarge readmission was higher when the cord was clamped before the first breath and that such risk decreased by approximately $20 \%$ per every additional 10 seconds lapsed until cord clamping.

Several update articles have reasserted the benefits of delayed cord clamping over immediate clamping and explored the different aspects that may explain the importance of beneficial mechanisms. ${ }^{29-30}$

FIGURE 1. Iron supply through the umbilical cord

Milligrams of iron received based on the time of cord clamping

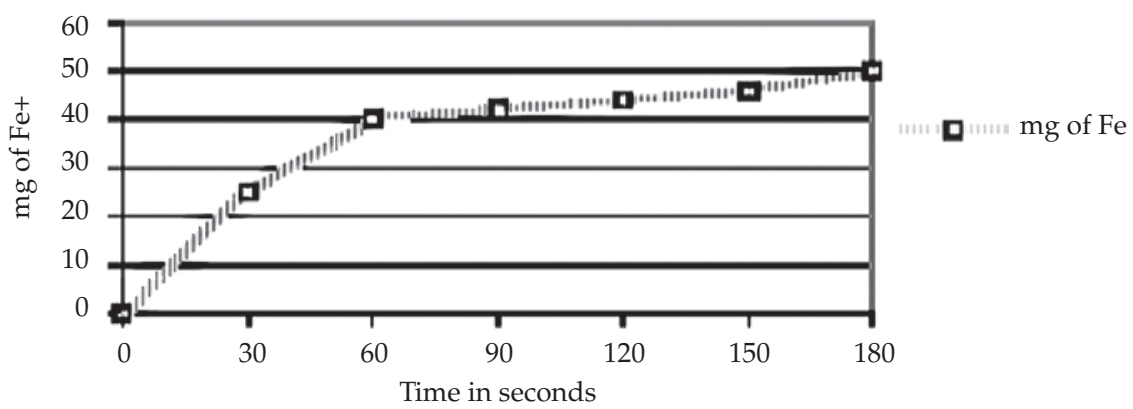

Source: Usher, Yao and Lind. 
Hooper et al. ${ }^{31}$ emphasize that immediate clamping results in a considerable limitation of venous return in the absence of breathing, thus reducing cardiac output, which remains very low until the infant starts breathing. When this occurs, lung aeration causes a particular increase in pulmonary circulation, which in turn rapidly boosts cardiac output, which is reflected by the clear increase in the infant's heart rate. It is worth noting that, during fetal life, the source of left ventricular preload is the blood flow from the placenta; this is replicated at birth while the blood from the placenta flows through the umbilical cord to the infant.

Once again, a big mistake is made when a NBI has apnea and cord clamping is hurried because, in the presence of a restricted cardiac output, the infant will remain cyanotic and have a reduced brain circulation.

This aspect reaffirms that cardiac output is the most important physiological mechanism and is necessary to prevent hypoxia-ischemia in the blood flow to the brain. This may only be achieved by leaving the cord unclamped until placental transfusion is completed. Thus, preload and cardiac output restriction will be prevented and the infant will have a more stable blood flow during adaptation.

Recent publications have emphatically underlined the importance of knowing and implementing physiological mechanisms in the approach to cord clamping timing in clinical practice. ${ }^{32,33}$

Undoubtedly, the generalized recommendation of immediate cord clamping -in place for several decades and based on no sound evidence- has inflicted countless damage on NBIs. To a great extent, this was the result of being unaware that placental transfusion provided an adequate volume loading that prevented a low cardiac output; this indicates that health care providers did not know the physiological processes involved in blood flow from the placenta to the infant.

In another recent article, Niermeyer approaches an extremely important aspect with great implications for everyday practice, and that is the relationship between cord clamping timing and the need to resuscitate the infant. ${ }^{34}$

Obstetricians and neonatologists agree on delayed cord clamping only if the NBI does not require resuscitation. Once it is determined that a NBI does require resuscitation, the umbilical cord is clamped immediately. However, this is neither justified nor supported by any study demonstrating that delayed cord clamping is detrimental to the recovery of an infant with asphyxia. On the contrary, there is a growing trend of encouraging resuscitation of TIs while leaving the cord unclamped..$^{35,36}$ The rationale for this is similar to what has been described above, given that, also in this case, physiological mechanisms play a critical role in the prevention of cardiac output reduction.

For this reason, the systematic clamping of the umbilical cord before attempting resuscitation is inadequate because, once again, it means not being aware of the physiological concepts related to neonatal transition. As indicated above, clamping should be delayed enough time, until at least after the first breath, and the same approach may be applied in the case resuscitation is required.

This aspect was assessed many years ago in an experimental study conducted in rhesus monkeys. ${ }^{37}$ For the study, a model was created to cause moderate depression at birth, and it was observed that if the cord was clamped immediately, it resulted in marked bradycardia accompanied by irregular breathing, panting, and subsequent apnea.

Clinical studies have endorsed the potential benefits of placental transfusion in the resuscitation of TIs, ${ }^{35,36}$ but scarce data have been published in the very small preterm infant population.

However, a recent study conducted by Kaempf et al..$^{38}$ provided interesting results after comparing the clinical course of 77 very low birth weight (VLBW) preterm newborn infants and 172 low birth weight (LBW) preterm newborn infants. They were all born at less than 35 weeks of gestation and cord clamping was delayed until 45 seconds, and were compared to the same number of historical controls born in the immediately previous period and subjected to early cord clamping. The Apgar score at 1 minute was higher among VLBW preterm infants subjected to delayed cord clamping (7 versus 5 , $p<0.001)$. Also, there was a remarkable reduction in the number of NBIs who required supplemental oxygen and ventilation at birth.

However, most likely, and for the time being, we may not recommend the systematic use of delayed cord clamping for all TIs who require resuscitation. Nonetheless, it may become part of the practice based on its high chances of being beneficial taking into account that the foundation 
for delayed cord clamping lies in physiological mechanisms, which are the safest alternative.

\section{Stem cells and placental transfusion}

The presence of stem cells in blood from the placenta is another highly relevant aspect because it plays a critical role, not only for infants but also for children and adults.

The number of stem cells is significantly higher in extremely preterm infants than in TIs. This has been demonstrated by Haneline et al., ${ }^{39}$ who also observed that the number of stem cells contained in the umbilical cord blood was higher than in older children and even higher than in the adult bone marrow. As per these findings, the number of stem cells in extremely preterm infants would be at its highest level than at any other time in human life.

In this physiological process, stem cells play multiple protective roles during fetal life and when the baby is born. In NBIs, the most important functions of these cells include mechanisms that regulate the growth and development of different organs (especially the central nervous system), an anti-inflammatory action, and the reduction of several diseases, such as respiratory distress syndrome, anemia, sepsis, intraventricular hemorrhage, and periventricular leukomalacia. There are other disorders, such as retinopathy of prematurity and necrotizing enterocolitis, for which their function has not been confirmed yet. ${ }^{40}$

Even though, at full term, the number of stem cells decreases, the amount provided with delayed cord clamping is more than enough, which is not the case with early clamping; and this is yet another sound argument against this practice.
In addition, umbilical cord blood contains a number of hematopoietic stem cells large enough to be used for transplantation in children, adolescents, and adults, ${ }^{41}$ a firmly rising hope. ${ }^{42,43}$

\section{Other aspects to be taken into consideration in relation to umbilical cord clamping timing}

\section{Plasma bilirubin levels}

Studies conducted in the 1970s found that infants undergoing delayed cord clamping had higher bilirubinemia values. ${ }^{5}$ An increase in the indication for phototherapy has also been described, but it is not unanimous; even though, a systematic review of clinical trials found that the indication for phototherapy was lower (at the cutoff point) among infants with early clamping. ${ }^{44}$

In our study, ${ }^{9}$ no differences were observed between groups in terms of bilirubin levels and the indication for phototherapy (Table 1).

\section{Anemia at birth and between 24 and 48 hours}

The presence of early anemia observed in our study ${ }^{9}$ was significantly higher among NBIs with early cord clamping (Table 2). The presence of anemia at birth is detrimental because it means iron stores will become insufficient in the short run, thus increasing the presence of iron deficiency anemia, together with its potential risks.

It is worth noting that a subsequent subgroup analysis -done after our study was publishedshowed that all NBIs with anemia (hematocrit $<45 \%$ ) at 24 and 48 hours had been born by C-section and had undergone early cord clamping. ${ }^{45}$ This information takes on special

TABLE 1. Plasma bilirubin levels between 36 and 48 hours

\begin{tabular}{|c|c|c|c|c|c|c|c|c|c|}
\hline \multirow[t]{2}{*}{ Treatment } & \multicolumn{8}{|c|}{ Blood bilirubin at $36-48$ hours } & \multirow[b]{2}{*}{ Q75 } \\
\hline & $\mathbf{N}$ & Missing & Min. & Max. & Mean & SD & Median & Q25 & \\
\hline Immediate clamping & 91 & 2 & 1 & 17.4 & 7.39 & 3.08 & 7.3 & 5.6 & 9 \\
\hline Clamping at 1 minute & 85 & 6 & 1 & 18.9 & 7.58 & 3.04 & 7.7 & 6.1 & 9 \\
\hline Clamping at 3 minutes & 90 & 2 & 1 & 14.6 & 6.99 & 2.98 & 7.2 & 5.0 & 9 \\
\hline Outcome measure & \multicolumn{3}{|c|}{$\begin{array}{c}\text { Immediate clamping } \\
\mathrm{n} / \mathrm{N}(\%)\end{array}$} & \multicolumn{3}{|c|}{$\begin{array}{c}\text { Clamping at } 1 \mathrm{~min} \\
\mathrm{n} / \mathrm{N}(\%)\end{array}$} & \multicolumn{3}{|c|}{$\begin{array}{c}\text { Clamping at } 3 \mathrm{~min} \\
\mathrm{n} / \mathrm{N}(\%)\end{array}$} \\
\hline $\begin{array}{l}\text { Bilirubin at } 36-48 \text { hours } \\
\text { higher than } 16 \mathrm{mg} / \mathrm{dL}\end{array}$ & \multicolumn{3}{|c|}{$2 / 91(2.20)$} & \multicolumn{3}{|c|}{$1 / 85(1.18)$} & \multicolumn{3}{|c|}{ 0/90 (0.0) } \\
\hline
\end{tabular}

SD: Standard deviation. 
relevance due to the extremely high number of C-sections performed at present, and reconfirms that delayed cord clamping should be the approach used in the case of a C-section.

\section{Oxidative stress}

It is known that free radicals cause different types of damage in certain situations, for example, at the time of delivery, when oxidative stress is confirmed in the mother, and especially in the NBI. Among other factors, the sudden change from the uterine environment with physiological hypoxia to the abrupt increase in partial pressure of oxygen $\left(\mathrm{pO}_{2}\right)$ at birth may likely release free radicals that are highly toxic to the infant. To avoid tissue damage, antioxidant systems should come into play during the first minutes after birth to reduce the harmful effects of oxidative stress.

Until recently, these mechanisms were not considered related to umbilical cord clamping timing. In 2014, Pediatrics ${ }^{46}$ published the first study that assessed the impact of early clamping (at 10 seconds) versus delayed clamping (at 2 minutes) on oxidative stress. Several inflammatory parameters were measured in healthy TIs who had been born from healthy mothers, by vaginal delivery, and who had an Apgar score at 1 and 5 minutes $\geq 7$. Results were conclusive and demonstrated that all protective elements measured in the study (erythrocyte catalase, superoxide dismutase, tumor necrosis factor receptor 2, etc.) were significantly higher among NBIs with delayed cord clamping.

Although future randomized studies are required, a very interesting research ground is charted that will provide important elements when deciding on the timing of cord clamping.

\section{Long-term neurodevelopment}

Only a few studies have assessed the impact that cord clamping timing has on long-term neurodevelopment, both in term and preterm infants. Recently published randomized studies have assessed neurodevelopment at 1 year old ${ }^{47}$ and at 4 years old ${ }^{48}$ in the same cohort of term infants with early cord clamping (within the first 10 seconds) versus delayed cord clamping (at 3 minutes). No differences were observed in the assessment at 1 year old, although boys with delayed clamping tended to show better results. The assessment at 4 years old is the first clinical research on neurodevelopment in the preschool population. No overall differences were found in the Wechsler Preschool and Primary Scale of Intelligence (WPPSI-III), although boys with delayed cord clamping obtained a significantly higher score than those with early cord clamping in the processing speed quotient, and they also obtained better scores and showed a significant differences in the movement tests, the fine motor area and the personal-social area of the Ages and Stages Questionnaire (ASQ).

It is worth noting that such better results were observed in children at a very low risk from a highly developed country (Sweden). This is worthy of consideration given that beneficial effects of delayed cord clamping on neurodevelopment may have a greater impact on vulnerable populations from a low social class and with a low education level. Although another study has been recently published, ${ }^{49}$ new trials are required to examine long-term effects of delayed cord clamping.

\section{Final remarks}

Based on every aspect pointed out in this article, and the sound evidence supporting them, there is no doubt that delayed cord clamping should be the standard of care for infants born at term or close to term.

TABLE 2. Central hematocrit in the first 48 hours

\begin{tabular}{lccc}
\hline & $\begin{array}{c}\text { Early clamping } \\
\mathbf{n = 9 0}\end{array}$ & $\begin{array}{c}\text { Clamping at } \mathbf{1} \text { min } \\
\mathbf{n = 9 0}\end{array}$ & $\begin{array}{c}\text { Clamping at } \mathbf{3} \text { min } \\
\mathbf{n = 9 2}\end{array}$ \\
\hline Hematocrit at $6 \mathrm{~h}<45 \%(\mathrm{n} \%)^{\mathbf{1}}$ & $8(8.9)$ & $1(1.1)$ & $0(0.0)$ \\
Hematocrit at $24-48 \mathrm{~h}<45 \%(\mathrm{n} \%)^{\mathbf{2}}$ & $15(16.9)$ & $2(2.3)$ & $3(3.3)$ \\
\hline
\end{tabular}

${ }^{1}$ Clamping at 1 minute versus early clamping: RR 0.3 (95\% CI: 0.02-0.8), P $<0.034$.

${ }^{1}$ Clamping at 3 minutes versus early clamping: RR 0.06 (95\% CI: 0.006-0.6), $\mathrm{P}<0.003$.

${ }^{2}$ Clamping at 1 minute versus early clamping: RR 0.13 (95\% CI: 0.035-0.50), $\mathrm{P}<0.0014$.

${ }^{2}$ Clamping at 3 minutes versus early clamping: RR 0.20 (95\% CI: 0.06-0.61), $\mathrm{P}<0.0027$.

Ceriani Cernadas JM, Carroli G, et al. Pediatrics 2006;117:e779-e786. 
To the best of my understanding, in the medical field, there is no other easy and inexpensive practice providing such short- and long-term benefits than simply respecting physiological mechanisms and waiting a few minutes.

Neonatologists and pediatricians need to consider the quantifiable effects of delayed cord clamping and advocate for major adherence to this practice in the delivery room.

In addition, I would like to recollect a reflection I made in a comment several years ago, ${ }^{50}$ which is still valid and may help us better understand why delayed cord clamping should be the standard practice:

The benefits of umbilical cord clamping not earlier than 2-3 minutes after birth are the result of physiological mechanisms; for this reason, it may not be considered an actual treatment but a practice that respects natural physiological mechanisms. Such benefits are mainly the product of allowing the infant to receive the blood volume that ought to have been in the child. That is to say, that placental transfusion is an unavoidable physiological outcome occurring in the first minutes of life and resulting from the redistribution of blood between the placenta and the infant.

Therefore, we must reflect upon the inadequate practice in relation to the timing of cord clamping because many health care providers are unaware of the fact that there is an undeniable physiological basis for delayed cord clamping.

Undoubtedly, nature has established that most of the blood volume present in the placenta ought to be in the infant, so why deprive the baby of it?

\section{REFERENCES}

1. Darwin E. Zoonomia: or, The laws of organic life. London: Johnson; 1801. Page 302.

2. Budin P. A quel moment doit-on pratiquer la ligature du cordon ombilical? Progr Med [Paris] 1875;3:765-7.

3. AGSP. 100 years on, and still no answer. Pediatrics 1975;55(6):813.

4. Usher R, Shephard M, Lind J. The blood volume of the newborn infant and placental transfusion. Acta Paediatr 1963;52:497-512.

5. Saigal S, O'Neill A, Surainder Y, Chua LB, et al. Placental transfusion and hyperbilirubinemia in the premature. Pediatrics 1972;49(3):406-19.

6. Yao AC, Lind J. Placental transfusion. Am J Dis Child 1974;127(1):128-41.

7. Saigal S, Usher RH. Symptomatic neonatal plethora. Biol Neonate 1977;32(1-2):62-72.

8. Linderkamp O, Versmold HT, Fendel H, Reigel KP, et al. Association of neonatal respiratory distress with birth asphyxia and deficiency of red cell mass in premature infants. Eur J Pediatr 1978;129(3):167-73.

9. Ceriani Cernadas JM, Carroli G, Pellegrini L, Otaño L, et al. The effect of timing of cord clamping on neonatal venous hematocrit values and clinical outcome at term: a randomized, controlled trial. Pediatrics 2006;117(4):e779-86.

10. Hutton EK, Hassan ES. Late vs Early Clamping of the Umbilical Cord in Full-term Neonates Systematic Review and Meta-analysis of Controlled Trials. JAMA 2007;297(11):1241-52.

11. McDonald SJ, Middleton P. Effect of timing of umbilical cord clamping of term infants on maternal and neonatal outcomes. Cochrane Database Syst Rev 2008;2(2):CD004074.

12. Ceriani Cernadas JM, Carroli G, Pellegrini L, Ferreira M, et al. Efecto del clampeo demorado del cordón umbilical en la ferritina sérica a los seis meses de vida. Estudio clínico controlado aleatorizado. Arch Argent Pediatr 2010;108(3):201-8.

13. Chaparro CM, Neufeld LM, Tena Alavez G, Eguia-Liz CR, ET al. Effect of timing of umbilical cord clamping on iron status in Mexican infants: a randomised controlled trial. Lancet 2006;367(9527):1997-2004.

14. van Rheenen P, Gruschke S, Brabin BJ. Delayed umbilical cord clamping for reducing anaemia in LBW infants implications for developing countries. Ann Trop Paediatr 2006;26(3):157-67.

15. van Rheenen P, Brabin BJ. Late umbilical cord clamping as an intervention for reducing iron deficiency anaemia in term infants in developing and industrialised countries. Ann Trop Paediatr 2004;24(1):3-16.

16. Gupta R, Ramji S. Effect of delayed cord clamping on iron stores in infants born to anemic mothers: a randomized controlled trial. Indian Pediatr 2002;39(2):130-5.

17. Linderkamp O. Placental transfusion: determinants and effects. Clin Perinatol 1982;9(3):559-92.

18. Pisacane A. Neonatal prevention of iron deficiency: placental transfusion is a cheap and physiological solution. BMJ 1996;312:136.

19. Geethanath RM, Ramji S, Thirupuram S, Rao YN. Effect of timing of cord clamping on the iron status of infants at 3 months. Indian Pediatr 1997;34(2):103-6.

20. Grajeda R, Perez-Escamilla R, Dewey K. Delayed clamping of the umbilical cord improves hematologic status of Guatemalan infants at 2 months of age. Am J Clin Nutr 1997;65(2):425-31.

21. van Rheenen P, De Moor L, Eschbach S, de Grooth H, et al. Delayed cord clamping and haemoglobin levels in infancy: a randomised controlled trial in term babies. Trop Med Int Health 2007;12(5):603-16.

22. Andersson O,Hellström-Westas L, Andersson D, Domellöf M. Effect of delayed versus early umbilical cord clamping on neonatal outcomes and iron status at 4 months: a randomised controlled trial. BMJ 2011;343:d7157.

23. Kim AJH, Warren JB. OptimalTiming of Umbilical Cord Clamping: Is the Debate Settled? Part 2 of 2: Evidence in Preterm and Term Infants, Alternatives, and Unanswered Questions. Neo Reviews 2015;16(5):e270-7.

24. Booth IW, Aukett MA. Iron deficiency anaemia in infancy and early childhood. Arch Dis Child 1997;76(6):549-54.

25. Carlson ES, Tkac I, Magid R, O'Connor MB, et al. Iron is essential for neuron development and memory function in mouse hippocampus. J Nutr 2009;139(4):672-9.

26. Szajewska H, Ruszczynski M, Chmielewska A. Effects of iron supplementation in nonanemic pregnant women, infants, and young children on the mental performance and psychomotor development of children: a systematic review of randomized controlled trials. Am J Clin Nutr 2010;91(6):1684-90.

27. Bhatt S, Alison BJ, Wallace EM, Crossley KJ, el al. Delaying cord clamping until ventilation onset improves cardiovascular function at birth in preterm lambs.J Physiol 2013;591(8): 2113-26.

28. Ersdal HL, Linde J, Mduma E, Auestad B, et al. Neonatal 
outcomefollowing cord clamping after onset of spontaneous respiration. Pediarics 2014;134(2);265-72.

29. Raju TNK. Timing of umbilical cord clamping after birth for optimizing placental transfusion. Curr Opin Pediatr 2013;25(2):180-7.

30. Duley L, Batey N. Optimal timing of umbilical cord clamping for term and preterm babies. Early Hum Dev 2013;89(11):905-8.

31. Hooper SB, Polglase GR, te Pas AB. A physiological approach to the timing of umbilical cord clamping at birth. Arch Dis Child Fetal Neonatal Ed 2015;100(4):F355-60.

32. Kluckow M, Hooper SB. Using physiology to guide time to cord clamping. Semin Fetal Neonatal Med 2015:20(4):22531.

33. BoereI, Roest AA, WallaceE, Ten Harkel AD, etal.Umbilical blood flow patterns directly after birth before delayed cord clamping. Archs Dis Child Fetal Neonatal Ed 2015;100(2): F121-5.

34. Niermeyer S, velaphi S. Promoting physiologic transition at birth: Re-examining resuscitation and the timing of cord clamping. Semin Fetal Neonatal Med 2013;18(6):385-92.

35. Hutchon D. Evolution of neonatal resuscitation with intact placental circulation. Clin Pract 2014;10(2):e58-61.

36. Perlman J, Kattwinkel J, Wyllie J, Guinsburg R, et al. Neonatal resuscitation: in pursuit of evidence gaps in knowledge. Resuscitation 2012;83(5):545-50.

37. Dawes GS, Jacobson HN, Mott JC, Shelley HJ, et al. The treatment of asphyxiated, mature foetal lambs and rhesus monkeys with intravenous glucose and sodiun carbonate. J Physiol 1963;169:167-84.

38. Kaempf JW, Tomlinson MW, Kaempf AJ, Wu Y, et al. Delayed umbilical cord clamping in premature neonates. Obstet Gynecol 2012;120(2 Pt 1):325-30.

39. Haneline LS, Marshall KP, Clapp DW. The highest concentration of primitive hematopoietic progenitor cells in cord blood is found in extremely premature infants. Pediatr Res 1996;39(5):820-5.

40. Lawton C, Acosta S, Watson N, González-Portillo C, et al. Enhancing endogenous stem cells in the newborn via delayed umbilical cord clamping. Neural Regen Res 2015;10(9):1359-62.

41. Tolosa JN, Park DH, Eve DJ, Klasko SK, et al. Mankind's first natural stem cell transplant. J Cell Mol Med 2010;14(3):488-95.

42. Chakraborty SK, Banu LA, Rahman MF, PaulS. Cord blood stem cells - a dream for future medicine. Mymensingh Med J 2014;23(3):614-20.

43. Milano F, Gooley T, Wood B, Woolfrey A, et al. Cord-Blood Transplantation in Patients with Minimal Residual Disease. N Engl J Med 2016;375(10):944-53.

44. McDonald SJ, Middleton P, Dowswell T, Morris PS. Effect of timing of umbilical cord clamping of term infants on maternal and neonatal outcomes. Cochrane Database Syst Rev 2013;(7):CD004074.

45. Ceriani Cernadas JM, Carroli G. Letter to the Editor. Pediatrics 2006;118:1317-9.

46. Díaz-Castro J, Florido J, Kajarabille N, Garrido-Sánchez M, et al. The Timing of Cord Clamping and Oxidative Stress in Term Newborns. Pediatrics 2014;134(2):257-64.

47. Andersson $\mathrm{O}$, Domellöf $\mathrm{M}$, Andersson D, HellströmWestas L. Effect of Delayed vs Early Umbilical Cord Clamping on Iron Status and Neurodevelopment at Age 12 Months A Randomized Clinical Trial. JAMA Pediatr 2014;168(6):547-54.

48. Andersson O, Lindquist B, Lindgren M, Stjernqvist K, et al. Effect of Delayed Cord Clamping on Neurodevelopment at 4 years of age: A Randomized Clinical Trial. JAMA Pediatr 2015;169(7):631-8.

49. RabeH,Erickson-Owens DA, Mercer JS. Long-term Followup of Placental Transfusion in Full-term Infants. JAMA Pediatr 2015;169(7):623-4.

50. Ceriani Cernadas JM, Durán P. Commentary, Cochrane review: early versus delayed umbilical cord clamping in preterm infants. WHO Reproductive Health Library, 2006. [Accessed on: October 19 $\left.{ }^{\text {th }}, 2016\right]$. Available at: http:// apps.who.int/rhl/pregnancy_childbirth/childbirth/3rd_ stage/jccom/en/ 